\title{
Cognitive Assessment in Patient of Chronic Obstructive Pulmonary Disease
}

\author{
Dr. S. H. Talib ${ }^{1}$, Dr. K. M. Raul ${ }^{2}$, Dr. Sandeep Sanap ${ }^{3}$, Dr. Vajed Mogal ${ }^{4}$, Dr. Vitthal Pawar ${ }^{5}$, \\ Dr. Vishal Dalvi ${ }^{6}$ \\ ${ }^{1,2,3,4,5,6}$ Department of Medicine, M.G.M. Medical College and Hospital, Aurangabad-431003. Maharashtra, India
}

\begin{abstract}
Backgrounds: Chronic obstructive pulmonary disease (COPD) is a complex, multisystem disorder. Traditional measures of disease severity, such as airflow limitation, are poor markers of relevant patient outcomes, largely because they do not reflect the multisystem nature of the disease. Identification, understanding, and assessment of all relevant co-morbidities in COPD are needed to better characterize the full clinical spectrum of the disease. Cognitive impairment is one such co-morbidity with an emerging clinical relevance. In present case control study we aimed to do Cognitive Assessment in Patient of Chronic Obstructive Pulmonary Disease compared to a matched referral control group without any disease. Among patients with established COPD, we evaluated the impact of disease severity and impairment of respiratory physiology on cognitive impairment. Staging of COPD was done according to Global Initiative for chronic obstructive Lung Disease (GOLD). Cognitive impairment was defined as a Mini mental State Exam (MMSE) score of <24 points. Aims and Objectives: To assess of cognitive function in a patients of COPD \& Co-relation of cognitive function with Global Initiative for chronic obstructive Lung Disease (GOLD) staging. Results: This study comprise of 99 patients in Case group suffering from COPD and 99 patients in Control arm not suffering from COPD. In case and control group 30.3\% were female while remaining 69.7\% were male. Comparison of MMSE score in cases and control group revealed that mean score in Attention \& calculation, recall and Language is significantly lower in case group compare to control group. Total MMSE score was also significantly lower in case group. MMSE core \& PO2 were significantly positively correlated. MMSE score increases with increase in the PO2 value. MMSE score and PCO2 were significantly negatively correlated. MMSE score increases with decrease in the PCO2 value. Conclusion: The present study concludes that patient with chronic obstructive pulmonary disease have significant cognitive impairment compared to healthy controls. The present study concludes that hypoxaemia, hypercapnia, lung function, smoking and BMI are important risk factors for cognitive impairment in COPD patients. Cognitive impairment was very high in severe COPD GOLD stage compare to mild and moderate COPD.
\end{abstract}

Keywords: Chronic obstructive pulmonary disease (COPD), Global Initiative for chronic obstructive Lung Disease (GOLD), Mini Mental status Examination (MMSE).

\section{Introduction}

Chronic obstructive pulmonary disease (COPD), a common medical ailment, results in significant morbidity and mortality. An estimated $9-10 \%$ of people around the globe suffer from the disease in both developed and less developed countries, and it ranks fourth among causes of death in the U.S. According to experts, it will become the third leading cause of death worldwide by 2020 as people continue to smoke and as the global population ages (Bellia et al.2003) ${ }^{1}$.

COPD is characterized by airflow obstruction; its breathrelated symptoms include wheezing, exertional dyspnea, chronic cough, and expectoration (Rennard, 1998) ${ }^{2}$. These symptoms, which may present in conjunction with hyperresponsiveness of the airway, are partly reversible.

WHO defines COPD as Chronic obstructive pulmonary disease (COPD)is a lung disease characterized by chronic obstruction of lung airflow that interferes with normal breathing and is not fully reversible ${ }^{3}$. Brain function may be adversely affected by COPD, and magnetic resonance imaging (MRI) has shown altered cerebral perfusion in patients with COPD who have cognitive dysfunction as a clinical manifestation ${ }^{4}$. The relationship between the many processes involved in an everyday cognitive task is complex, but cognitive ability is usually broken down into domains concerning memory, learning ability, attention/ concentration, abstract thinking, and problem solving 5 . Cognitive dysfunction reduces the level of functioning as assessed by activities of daily living ${ }^{6}$ and it is associated with poor compliance with both medication and oxygen therapy, and poor compliance increases the risk of acute exacerbation ${ }^{7}$.

Hypoxemia and hypercapnia appear to aggravate cognitive dysfunction in patients with $\mathrm{COPD}^{8}$ and in a multicenter study of 302 patients with mild, moderate and severe hypoxia, the frequency of cognitive dysfunction was $27 \%$ in patients with mild hypoxia and $61 \%$ in patients suffering from severe hypoxia 9 . Increasing age and low level of education were also associated with cognitive impairment. Furthermore, a direct association between cerebral hypoperfusion and cognitive dysfunction has been described. In addition, cognitive performance might also be affected in patients with normal oxygen saturation ${ }^{10}$. Several features of COPD may contribute to impaired cognitive function, including hypoxemia and co-morbid cardiovascular disease $^{11}$. In addition, COPD may lead patients to curtail their physical activity which may, in turn, further increase the risk of cognitive Impairment ${ }^{12}$.

The majority of the studies (62\%) concerned patients over 40 yrs of age, in particular those aged between 40 and 64 yrs. The prevalence of COPD increases with age, with a five-fold increased risk for those aged over 65 yrs compared with patients aged less than $40 \mathrm{yrs}^{13}$.

\section{Volume 4 Issue 12, December 2015}




\section{International Journal of Science and Research (IJSR) \\ ISSN (Online): 2319-7064 \\ Index Copernicus Value (2013): 6.14 | Impact Factor (2014): 5.611}

Prevalence of COPD and it's association with smoking in various population studies from India ${ }^{14}$.

\begin{tabular}{|c|c|c|c|c|}
\hline & \multirow[t]{2}{*}{ Population } & \multicolumn{3}{|c|}{ COPD prevalence (\%) } \\
\hline & & Men & Women & $\begin{array}{l}\text { M.F } \\
\text { Rabo }\end{array}$ \\
\hline Wig (1984) & Rural Delhi & 3.36 & 2.54 & 1.3 \\
\hline Slkand (1965) & Delni & 7.0 & 4.3 & 1.6 \\
\hline Viswanathan (1968) & Patns & 2.12 & 1.33 & 1.6 \\
\hline Bhattacharya (1975) & Rural UP & 6.67 & 4.48 & 1.6 \\
\hline Radha (1977) & New Dew & 8.1 & 4.6 & 1.8 \\
\hline Thiruvengadam (1977) & Madras & 1.9 & 1.2 & 1.6 \\
\hline \multirow[t]{2}{*}{ Viswanathan (1977) } & Delhi Rural & 4.7 & 3.5 & 1.3 \\
\hline & Urban & 8.0 & 4.3 & 1.9 \\
\hline Charan (1877) & Rural Punjab & 2.28 & 1.63 & 1.4 \\
\hline \multirow[t]{2}{*}{ Malik (1966) } & N. India Rural & 9.4 & 4.9 & 1.9 \\
\hline & Urban & 3.7 & 1.6 & 23 \\
\hline \multirow[t]{2}{*}{ Jindal (1980) } & N. India Rural & 8.2 & 3.9 & 1.6 \\
\hline & Urban & 4.2 & 1.6 & 2.6 \\
\hline Ray (1995) & South Incia & 408 & 2.55 & 1.6 \\
\hline
\end{tabular}

One of the earliest studies to know the prevalence of COPD in India was carried out by Wig et al in $1964^{15}$ in rural Delhi. The prevalence was 3.36 percent in males and 2.54 percent in females in this study. Viswanathan in $1966^{16}$ reported 2.12 percent prevalence in males and 1.33 per cent in females in Patna. Radha and colleagues ${ }^{17}$ noticed that the prevalence in New Delhi in 1977 was 8.1 percent in men and 4.6 percent in women. Jindal in $1993^{18}$ reported that the prevalence was 6.2 percent in men and 3.9 percent in women in rural area, and 4.2 and 1.6 percent, respectively in urban area. All these studies were from north India and information from south India was scanty. Thiruvengadam et al in $1977^{19}$ from Madras (south India) reported the prevalence of COPD of 1.9 percent in males and 1.2 percent in females. However, Ray et al in $1995^{20}$ from south India found that the prevalence was 4.08 percent in males and 2.55 percent in females. Recently, the Indian Study on Epidemiology of Asthma, Respiratory Symptoms and Chronic Bronchitis in Adults (INSEARECH) involving a total of 85105 men, 84470 women from 12 urban and 11 rural sites was reported. This study had shown that the overall prevalence of chronic bronchitis in adults $>35 \mathrm{yr}$ was 3.49 percent (ranging $1.1 \%$ in Mumbai to $10 \%$ in Thiruvananthapuram). Thus there are wide variations in the prevalence of COPD in India subcontinent. Based on this study, the national burden of chronic bronchitis was estimated as 14.84 million.

The prevalence of COPD increases with age ${ }^{21}$. In the course of life, there is a physiological decline in respiratory function which begins around the age of 30-40 yrs. Because of the increase in life expectancy in developed countries, the proportion of older subjects with COPD also increases.

The hallmark of COPD is airflow obstruction ${ }^{22}$. Pulmonary function testing shows airflow obstruction with a reduction in FEV1 and FEV1/FVC. With worsening disease severity, lung volumes may increase, resulting in an increase in total lung capacity, functional residual capacity, and residual volume. In practice, Cognitive abilities are mainly inferred from behavior, which itself is determined by a wide variety of neurological, psychological and emotional factors ${ }^{23}$. A key mechanism proposed for cognitive dysfunction in COPD is neuronal damage mediated through hypoxia, but it has also been suggested that oxygen-dependant enzymes which are important in the synthesis of neurotransmitters, such as acetylcholine, may be affected ${ }^{24}$.

\section{Aims and Objectives \\ - Assessment of cognitive function in a patients of COPD \\ - Co-relation of cognitive function with Global Initiative for chronic obstructive Lung Disease (GOLD) staging.}

\section{Material and Methods}

\section{Study Setting}

The present study was conducted in MGM Medical college \& Hospital, Aurangabad, a tertiary care teaching hospital. The hospital mainly caters urban, peri urban and rural population of Aurangabad. This study was conducted among the COPD patients admitted to the hospital.

\section{Study Type}

The current study was a matched case control study. The eligible patients of COPD were form a Case group while controls were selected from the health individuals accompanying to patients in the hospital.

\section{Study Period}

The study took approximately two and half year to complete. Review literature and questionnaire preparation took approximately 12 months. The period of data collection was spread over 16 months after approval from the scientific and ethical Committee. More than 2 months required to data analysis and preparation of thesis report.

\section{Sample Size}

99 Cases of stable COPD patients

99 Healthy controls matched with age and sex of COPD patient.

\section{Selection of Cases}

All patients with respiratory complains admitted to the ward were investigated in detail to find out COPD. Those who were diagnosed having COPD were assessed for eligibility criteria. Patients fulfilling the ${ }^{25}$ eligibility criteria were included in the study after consent. Eligibility criteria for cases were as follows:

\section{Inclusion criteria:}

All the patients of Chronic Obstructive Pulmonary Disease admitted in MGM Medical college \& Hospital, Aurangabad; medically stable; and with at least primary school certificate.

\section{Exclusion criteria:}

COPD patients with Co existing any other significant systemic disease; medically unstable; and patient suffering from any psychiatric disorder.

\section{Selection of Control:}

Controls were selected after the selection of cases keeping ratio of 1:1 cases to control. Age and sex matched control were selected from the patients relatives accompanying to

\section{Volume 4 Issue 12, December 2015}




\section{International Journal of Science and Research (IJSR) \\ ISSN (Online): 2319-7064 \\ Index Copernicus Value (2013): 6.14 | Impact Factor (2014): 5.611}

the hospital. After the consent all control were investigated in detailed to rule out presence of COPD.

\section{Data Collection}

For all eligible cases and controls a predesigned questionnaire was used to record patients' data. Initially history taking was done to record socio-demographic and personnel information. The selected cases and controls were subjected to thorough clinical investigations with special references to respiratory system. For each specific symptom/ specific site a detailed history and relevant details was taken. All patients were assessed with spirometry and Staging was done according to Global Initiative for chronic obstructive Lung Disease (GOLD).

\section{Statistical Analysis}

It will be conducted using (SPSS) statistical packages for social science Version 18. Data will be represented using bar diagram, Pie diagram etc. Bivaried comparisons will be carried out using ' $t$ ' test and chi square test for qualitative variables. We will try to use logistic regression to examine the association between COPD and the risk of cognitive impairment.

\section{Ethical Consideration}

As this study involve hospital patients which vulnerable group all care was taken to protect ethical rights of the patients. An approval was sought from the institutional ethical committee before the start of the study. For the eligible cases and controls were informed in detail about the study and it's process. They were also explained about probable benefits and potential risk associated with the study in vernacular language. Then after, a written consent was taken in vernacular language. A high degree of confidentiality was maintained at all level from recruitment to data collection to analysis.

\section{Observations and Results}

This study comprise of 99 patients in Case group suffering from COPD and 99 patients in Control arm not suffering from COPD. Following tables shows observation of the study.

\section{Table 1:}

There was no statistical difference in mean age of both the group ( $p>0.05)$. BMI was lower in case group and this difference was statistically significant $(\mathrm{p}<0.05)$.

Arterial blood gas analysis was carries out in all subjects of case and control groups. In cases mean $\mathrm{PO}{ }_{2}$ was 86.04 with standard deviation of 5.95 while mean $\mathrm{PCO} 2$ was 41.12 with standard deviation of 4.37. In control group mean $\mathrm{PO}_{2}$ was 93.07 with standard deviation of 3.25 while mean PCO2 was 38.00 with standard deviation of 2.29 .

\begin{tabular}{|l|l|l|l|l|l|}
\hline Variables & \multicolumn{2}{|c|}{ Case (n=99) } & \multicolumn{2}{l|}{ Control (n=99) } & \multirow{2}{*}{ P value } \\
\cline { 2 - 5 } & Mean & SD & Mean & SD & \\
\hline Age $($ in years $)$ & 56.88 & 9.20 & 56.92 & 9.19 & 0.975 \\
\hline BMI $\left(\mathrm{kg} / \mathrm{m}^{2}\right)$ & 21.34 & 3.07 & 22.22 & 2.53 & 0.029 \\
\hline $\mathrm{PO}_{2}$ & 86.04 & 5.95 & 93.07 & 3.25 & - \\
\hline $\mathrm{PCO}_{2}$ & 41.12 & 4.37 & 38.00 & 2.29 & - \\
\hline
\end{tabular}

Table 2:

In case and control group $30.3 \%$ were female while remaining $69.7 \%$ were male. Distribution of male and female is equal in case and control group because controls were selected after matching sex and age. Observed value proportion of exposure to chulha smoke, smoking \& cognitive impairment is much higher and this difference was statistically highly significant by using chi-square test. The calculated $\mathrm{p}$ value was less than 0.01 .

\begin{tabular}{|c|c|c|c|c|c|c|}
\hline \multirow{2}{*}{ Variables( ) } & \multicolumn{2}{|c|}{ Case } & \multicolumn{2}{|c|}{ Control } & \multirow[t]{2}{*}{ Total } & \multirow[t]{2}{*}{$P$ value } \\
\hline & Freq & $\%$ & Freq & $\%$ & & \\
\hline \multicolumn{7}{|l|}{$(\operatorname{Sex})$} \\
\hline Male & 30 & $30.3 \%$ & 30 & $30.3 \%$ & 60 & 1.000 \\
\hline Female & 69 & $69.7 \%$ & 69 & $69.7 \%$ & 138 & \\
\hline Total & 99 & $100 \%$ & 99 & $100 \%$ & 198 & \\
\hline \multicolumn{7}{|l|}{ ( Smoking ) } \\
\hline Yes & 69 & $69.7 \%$ & 27 & $27.3 \%$ & 96 & 0.001 \\
\hline No & 30 & $30.3 \%$ & 72 & $72.7 \%$ & 102 & \\
\hline Total & 99 & $100 \%$ & 99 & $100 \%$ & 198 & \\
\hline \multicolumn{7}{|c|}{ (Chulha smoke exposure) } \\
\hline Yes & 28 & $28.3 \%$ & 10 & $10.1 \%$ & 38 & 0.001 \\
\hline No & 71 & $71.7 \%$ & 89 & $89.9 \%$ & 160 & \\
\hline Total & 99 & $100 \%$ & 99 & $100 \%$ & 198 & \\
\hline \multicolumn{7}{|c|}{ (Cognitive impairment) } \\
\hline Mild & 11 & $11.1 \%$ & 1 & $1 \%$ & 12 & 0.003 \\
\hline No & 88 & $88.9 \%$ & 98 & $99 \%$ & 186 & \\
\hline Total & 99 & $100 \%$ & 99 & $100 \%$ & 198 & \\
\hline
\end{tabular}

Table 3: All subjects including cases and controls were assessed for MMSE score. Comparison of MMSE score in cases and control group revealed that mean score in Attention \& calculation, recall and Language is significantly lower in case group compare to control group. Total MMSE score was also significantly lower in case group. In orientation and registration there was no significant difference in case and control.

\begin{tabular}{|l|l|l|l|l|l|}
\hline \multirow{2}{*}{$\begin{array}{l}\text { MMSE Score } \\
\text { category }\end{array}$} & Case & \multicolumn{2}{l|}{ Control } & P value \\
\cline { 2 - 6 } & Mean & SD & Mean & SD & \\
\hline Orientation & 9.64 & 0.68 & 9.93 & 1.46 & 0.074 \\
\hline Registration & 2.98 & 0.14 & 2.99 & .10 & 0.536 \\
\hline $\begin{array}{l}\text { Attention } \\
\text { Calculation }\end{array}$ & 4.06 & 0.89 & 4.88 & .33 & $<0.001$ \\
\hline Recall & 2.22 & 0.60 & 2.85 & .39 & $<0.001$ \\
\hline Language & 8.68 & 0.60 & 8.83 & .43 & 0.043 \\
\hline Total score & 27.64 & 2.13 & 29.47 & .99 & $<0.001$ \\
\hline
\end{tabular}




\section{International Journal of Science and Research (IJSR) \\ ISSN (Online): 2319-7064 \\ Index Copernicus Value (2013): 6.14 | Impact Factor (2014): 5.611}

Table 4: Except for Registration, MMSE score was significantly lower as the severity of COPD increases. He same was also reflected in total score. Total MMSE score decreased as the severity of COPD increases.

\begin{tabular}{|c|c|c|c|c|c|c|c|}
\hline \multirow{3}{*}{$\begin{array}{c}\text { Cognitive functions MMSE } \\
\text { Score }\end{array}$} & \multicolumn{6}{|c|}{ GOLD Stage of COPD } & \multirow[t]{3}{*}{$\mathrm{P}$ value } \\
\hline & \multicolumn{2}{|c|}{ Mild $(n=18)$} & \multicolumn{2}{|c|}{$\operatorname{Mod}(n=58)$} & \multicolumn{2}{|c|}{ Severe $(n=23)$} & \\
\hline & Mean & $S D$ & Mean & $S D$ & Mean & $S D$ & \\
\hline Orientation & 9.72 & .83 & 9.79 & .49 & 9.17 & .78 & .001 \\
\hline Registration & 3.00 & .00 & 2.98 & .13 & 2.96 & .21 & .606 \\
\hline Attention \& Calculation & 4.61 & .61 & 4.22 & .77 & 3.22 & .80 & .000 \\
\hline Recall & 2.67 & .49 & 2.28 & .52 & 1.74 & .54 & .000 \\
\hline Language & 8.61 & .70 & 8.83 & .38 & 8.35 & .83 & .004 \\
\hline Total score & 28.61 & 1.91 & 28.14 & 1.52 & 25.61 & 2.39 & .000 \\
\hline
\end{tabular}

Table 5: Proportion of male was $72.2 \%$ in mild COPD, $65.5 \%$ in moderate COPD and $78.3 \%$ in severe COPD. Thus proportion of male was higher in all three categories and it was nearly similar in all three categories. Proportions of subjects having exposure to chulha smoke were $16.7 \%$ in mild COPD, $34.5 \%$ in moderate COPD and $21.7 \%$ in severe COPD. Thus proportion of chulha smoke exposure was higher in moderate category followed by severe category. Proportion of smoker was $72.2 \%$ in mild COPD, $65.5 \%$ in moderate COPD and $78.3 \%$ in severe COPD. Thus proportion of male was higher in all three categories and it was nearly similar in all three categories. Mild cognitive impairment rate was $5.6 \%$ in mild COPD, $5.2 \%$ in moderate COPD and $30.4 \%$ in severe COPD. Thus cognitive impairment was very high in severe COPD GOLD stage compare to mild and moderate COPD.

\begin{tabular}{|c|c|c|c|c|c|c|}
\hline \multirow[t]{3}{*}{ Variables( ) } & \multicolumn{6}{|c|}{ GOLD Stage of COPD } \\
\hline & \multicolumn{2}{|c|}{ Mild (n=18) } & \multicolumn{2}{|c|}{$\operatorname{Mod}(\mathrm{n}=58)$} & \multicolumn{2}{|c|}{ Severe $(n=23)$} \\
\hline & Freq & $\%$ & Freq & $\%$ & Freq & $\%$ \\
\hline \multicolumn{7}{|l|}{$(\operatorname{Sex})$} \\
\hline Female & 5 & $27.8 \%$ & 20 & $34.5 \%$ & 5 & $21.7 \%$ \\
\hline Male & 13 & $72.2 \%$ & 38 & $65.5 \%$ & 18 & $78.3 \%$ \\
\hline Total & 18 & $100 \%$ & 58 & $100 \%$ & 23 & $100 \%$ \\
\hline \multicolumn{7}{|c|}{ (Chulha smoke exposure) } \\
\hline Yes & 3 & $16.7 \%$ & 20 & $34.5 \%$ & 5 & $21.7 \%$ \\
\hline No & 15 & $83.3 \%$ & 38 & $65.5 \%$ & 18 & $78.3 \%$ \\
\hline Total & 18 & $100 \%$ & 58 & $100 \%$ & 23 & $100 \%$ \\
\hline \multicolumn{7}{|l|}{ (Smoker) } \\
\hline Yes & 13 & $72.2 \%$ & 38 & $64.5 \%$ & 18 & $78.3 \%$ \\
\hline No & 5 & $27.8 \%$ & 20 & $35.5 \%$ & 5 & $21.7 \%$ \\
\hline Total & 18 & $100 \%$ & 58 & $100 \%$ & 23 & $100 \%$ \\
\hline \multicolumn{7}{|c|}{ (Cognitive impairment) } \\
\hline Mild & 1 & $5.6 \%$ & 3 & $5.2 \%$ & 7 & $30.4 \%$ \\
\hline No & 17 & $94.4 \%$ & 55 & $94.8 \%$ & 16 & $69.6 \%$ \\
\hline Total & 18 & $100 \%$ & 58 & $100 \%$ & 23 & $100 \%$ \\
\hline
\end{tabular}

Table 6: Proportion of smoker were higher in mild cognitive impairment group, however this difference was not statistically significant $(\mathrm{P}>0.05)$. $\mathrm{PO}_{2}$ as $76.39 \mathrm{mmHg}$ in mild cognitive impairment group while it was $87.25 \mathrm{mmHg}$ in no cognitive impairment group. This difference was statistically significant $(\mathrm{P}<0.01) . \mathrm{PCO}_{2}$ was $47.36 \mathrm{mmHg}$ in mild cognitive impairment group while it was $40.34 \mathrm{mmHg}$ in no cognitive impairment group. This difference was statistically significant $(\mathrm{P}<0.01)$.

\begin{tabular}{|c|c|c|c|c|c|c|}
\hline \multicolumn{2}{|c|}{ Variables } & \multicolumn{4}{|c|}{ Cognitive impairment } & \multirow{2}{*}{ Pvalue } \\
\hline & & $\begin{array}{c}\text { Mild } \\
(n=11)\end{array}$ & $\%$ & $\begin{array}{c}N o \\
(n=88)\end{array}$ & $\%$ & \\
\hline \multirow[t]{2}{*}{ Smoking } & Yes & 9 & $81.8 \%$ & 60 & $68.2 \%$ & 0.353 \\
\hline & No & 2 & $18.2 \%$ & 28 & $31.8 \%$ & \\
\hline \multicolumn{2}{|l|}{$\mathrm{PO}_{2}$} & 76.39 & 5.935 & 87.25 & 4.752 & $<0.01$ \\
\hline \multicolumn{2}{|c|}{$\mathrm{PCO}_{2}$} & 47.36 & 6.592 & 40.34 & 3.308 & $<0.01$ \\
\hline
\end{tabular}

\section{Discussion}

The present study was conducted to assess cognitive function in patients of Chronic Obstructive Pulmonary Disease. Chronic obstructive pulmonary disease (COPD) is a pathological condition of the respiratory system commonly diagnosed in the fifth decade of life and characterized by a high socioeconomic impact ${ }^{26}$. COPD is only partially reversible and can progressively affect the function of other organs (eg, heart, vasculature, muscles, kidney, liver, gastroenteric apparatus, and brain) causing different comorbidities of various severities including cognitive impairment. COPD effects on cognition are still poorly understood; indeed, this comorbidity has not been investigated as extensively as other pathologies ${ }^{27}$; Cognitive function impairment was found to be associated with severe pulmonary dysfunction long ago, although its prevalence varied from study to study ${ }^{28}$ and was dependent on the specific diagnostic criteria adopted, the methods used for assessing the impairment, and the number of subjects investigated $^{29}$.

Several studies investigating cognition in subjects with chronic airflow limitation had methodological limitations, including lack of clinical assessment of airflow impairment; a specific focus on cognitive impairment in elderly subjects with severe respiratory conditions; a lack of interest in subjects without a defined respiratory disease; a lack of extensive comparison of cognitive impairment in COPD subjects versus subjects with other chronic airway disorders and/or healthy subjects; a lack of multiple psychometric tools; and small sample sizes.

\section{Demographic Profile}

The present study comprises of 99 patients in Case group suffering from COPD and 99 patients in control arm not suffering from COPD. In case and control group 30.3\% were female while remaining $69.7 \%$ were male.

In the study conducted by William W. Hung, ${ }^{30,31}$ the proportion of female cases in the no COPD, COPD and Severe COPD group were $56.7 \%, 57.4 \%$ and $62.9 \%$. The

\section{Volume 4 Issue 12, December 2015}




\section{International Journal of Science and Research (IJSR) ISSN (Online): 2319-7064 \\ Index Copernicus Value (2013): 6.14 | Impact Factor (2014): 5.611}

association between gender and COPD cases was found to be statistically insignificant.

In the study conducted by Neeta Thakur et al, ${ }^{32}$ the proportion of female gender in COPD group was $57.4 \%$ and in the control group was $61 \%$. In the study conducted by Roberto W Dal Negro, ${ }^{33} 68.1 \%$ were males and $31.9 \%$ were females. The results of this study were comparable to the present study. In the study conducted by Jing Li and Guang$\mathrm{He} \mathrm{Fei},{ }^{34}$ the proportion of female was $38 \%$. Mean age of subjects in case group was 56.88 years while it was 56.92 years in control group. There was no statistical difference in mean age of both the group $(\mathrm{p}>0.05)$. In the study conducted by Neeta Thakur et al, the mean age of the cases in the COPD group is 58.2 (SD 6.2) years and in the control group is 58.5 (SD 6.2) years. In the study conducted by Gupta et al, ${ }^{35}$ the mean age of the cases in the COPD group was 57.25 (SD 9.07) years and in the control group is 56.9 (SD 9.21) years $(\mathrm{p}>0.05)$. In the study conducted by Jing $\mathrm{Li}$ and Guang-He Fei, ${ }^{34}$ the mean age was 66.48, 69.27 and 67.60 years in control group, mild to moderate COPD group and severe COPD group respectively. BMI was lower in case group and this difference was statistically significant $(\mathrm{p}$ $<0.05$ ). In the study conducted by Roberto W Dal Negro, ${ }^{33}$ the mean BMI in COPD group was 27.1 (SD 5.6) while in the asymptomatic smokers it was 26.9 (SD 4.5). The BMI in the present study was much lower than the study conducted by Roberto W Dal Negro. It was observed from the Roberto W Dal Negro study that substantial cognitive dysfunction was slightly related to BMI.

Smokers have a more chances of developing COPD in the long run. In the study conducted by Gupta et al, ${ }^{35}$ none of the control was smoker while in case group average cigarette smoking per day was 39.95 (SD 20.94). In the study conducted by Manju Bhaskar, ${ }^{36} 80 \%$ cases had smoking abuse in case group and $30 \%$ cases in the control group had smoking abuse. The association between the smoking and COPD occurrence was statistically significant in Manju Bhaskar Study. The most important cause of COPD is smoking. Not only active smoking, but also passive exposure to smoking, air pollution and occupational chemicals contribute to a higher risk for COPD in both high- and lowincome countries. Because of the slow progression of the disease, COPD is frequently not diagnosed until after the age of 40. It's for this reason that the overall prevalence is low before the age of 40 and increases with age. As a result of an increase of smoking amongst women and a greater risk of exposure to air pollution, prevalence amongst men and women is almost equal today (World Health Organization [WHO], 2009).

Arterial blood gas analysis was carries out in all subjects of case and control groups. In cases mean $\mathrm{PaO}$ was 86.04 with standard deviation of 5.95 while mean $\mathrm{PaCO} 2$ was 41.12 with standard deviation of 4.37 . In ${ }^{37}$ control group mean $\mathrm{PaO}$ was 93.07 with standard deviation of 3.25 while mean $\mathrm{PaCO} 2$ was 38.00 with standard deviation of 2.29. In Pulmonary Function Test, conducted in cases only, mean FEV1 was 1.42 with standard deviation of 0.49 . In the study conducted by Roberto W Dal Negro, ${ }^{33}$ the mean $\mathrm{PaO} 2$ in the COPD group is 69.5 (SD 11.3) while in the asymptomatic smokers group it was 81.5 (6.1) while mean $\mathrm{PaCO} 2$ in the
COPD group is 43.5 (SD 10.6) while in the asymptomatic smokers group it was 38.3 (7.7). In the present study, $\mathrm{PaO}$ was $76.39 \mathrm{mmHg}$ in mild cognitive impairment group while it was $87.25 \mathrm{mmHg}$ in no cognitive impairment group. This difference was statistically significant $(\mathrm{P}<0.01)$ while $\mathrm{PaCO} 2{ }^{38}$ was $47.36 \mathrm{mmHg}$ in mild cognitive impairment group while it was $40.34 \mathrm{mmHg}$ in no cognitive impairment group. This difference was statistically significant $(\mathrm{P}<0.01)$. In the study conducted by Jing Li and Guang-He Fei, ${ }^{34}$ the mean $\mathrm{PaO} 2$ was 91.82, 71.89 and 66.36 in control group, mild to moderate COPD group and severe COPD group respectively. The difference was found to be significant. In the same study conducted by Jing Li and Guang-He Fei, ${ }^{34}$ the mean $\mathrm{PaCO} 2$ was $37.00,40.27$ and 48.27 in control group, mild to moderate COPD group and severe COPD group respectively. The difference was found to be significant. In the present study mean FEV1 was 1.42 with standard deviation of 0.49 in case group. In the study conducted by Gupta et al, ${ }^{35}$ the mean FEV1 of the cases in the COPD group was 1.48 (SD 0.50) which is comparable with our finding. In the study conducted by Jing $\mathrm{Li}$ and Guang-He Fei, the mean FEV1 (\% of predicted FEV) was 106.1, 61.14 and 34.15 liters in control group, mild to moderate COPD group and severe COPD group respectively. The difference was found to be significant.

\section{COPD and MMSE -}

All cases and controls were assessed for MMSE score. Comparison of MMSE score in cases and control group revealed that mean score in Attention, recall and Language is significantly lower in case group compare to control group. Total MMSE score was also significantly lower in case group. In orientation and registration there was no significant difference in case and control. In the study conducted by Manju Bhaskar, ${ }^{36}$ the mean score in orientation was 9.40 (SD 0.855) in COPD group and 9.567 (SD 0.728) in control group, in registration was 3.0 (SD 0.0) in COPD group and 3.0 (SD 0.0) in control group, in attention was 4.36 (SD 0.89) in COPD group and 4.90 (SD 0.305 ) in control group, in recall was 2.167 (SD 0.874) in COPD group and 2.60 (SD 0.49) in control group, in language was 7.933 (SD 0.254) in COPD group and 8.00 (SD 0.0) in control group, in construction was 0.933 (SD 0.254 ) in COPD group and 1.0 (SD 0.0) in control group. The total score in the COPD group was 27.833 (SD 2.245) and 29.167 (SD 1.147) in control group. In the study conducted by James $W$. Dodd, the mean MMSE score in COPD stable group was 28 (SD 2), in COPD exacerbation group was 27 (SD 4) and control group was 30 (SD 1). The association between the MMSE score and COPD group was statistically significant. In the study conducted by Gupta et al, ${ }^{35,39}$ the mean MMSE score of the cases in the COPD group was 22.48 (SD 2.42) and in the control group is 27.85 (SD 1.51) and similar to the present study the difference was significant $(\mathrm{p}<0.001)$ indicating that MMSE score is lower in COPD cases. In the study conducted by Jing $\mathrm{Li}$ and Guang-He Fei, ${ }^{34}$ the mean MMSE score was $28,24.57$ and 22.15 years in control group, mild to moderate COPD group and severe COPD group respectively. The difference was found to be significant $(\mathrm{p}<0.001){ }^{40}$ There are total 12 cases of mild cognitive impairment among the total 198 subjects. The mild cognitive impairment rate was $11.1 \%$ in case group

\section{Volume 4 Issue 12, December 2015}




\section{International Journal of Science and Research (IJSR) ISSN (Online): 2319-7064 \\ Index Copernicus Value (2013): 6.14 | Impact Factor (2014): 5.611}

while it was $1.0 \%$ in control group. So, the cognitive impairment is higher in case group and this difference was statistically significant $(\mathrm{p}<0.01)$. In the present study, MMSE score and $\mathrm{PaO}$ ere significantly positively correlated. MMSE score increases with increase in the $\mathrm{PaO} 2$ value. MMSE score and $\mathrm{PaCO}^{41}$ were significantly negatively correlated. MMSE score increases with decrease in the $\mathrm{PaCO} 2$ value. In the early stages of COPD, The most often reported findings of cognitive impairment in patients with COPD are impaired attention functions ( Klein et al., 2009;). ${ }^{42}$ An increase in information processing speed, less accuracy in responses to verbal and visual stimuli, impaired orientation, executive and constructive functions have also often been reported in COPD patients (Özge et al., 2006). ${ }^{43}$ One study, however, reported that visual attention abilities were well-preserved compared to he group of normal elderly adults, but they noted that this was most likely due to distractibility of the group of older subjects (Antonelli Incalzi et al., 1993). ${ }^{44}$

Memory is also reported to be impaired in patients with COPD, most often in the more severe stages of COPD. For example, significant impairments were found on immediate free recall, verbal memory, recent memory and long-term storage strategies in patients with COPD (Özge et al., 2006). ${ }^{43}$ Liesker et al. (2003) ${ }^{45}$ however, did not find a significant difference for memory, possibly because of the use of medicine by patients with COPD or perhaps because the COPD wasn't severe enough in the patients.

\section{GOLD Stage of COPD and Cognitive Impairment -}

In the present study, all cases were also divided according to the GOLD staging of COPD. In mild COPD there were 18 subjects while in moderate category there were 58 subjects while there were 23 subjects having severe COPD GOLD staging. In the study conducted by Jing Li and Guang-He $\mathrm{Fei}^{34}$

37 subjects were having mild to moderate COPD Gold staging while 48 subjets were classified as Severe COPD GOLD staging. Except for the Registration, MMSE score was significantly lower as the severity of COPD increases. The same was also reflected in total score. Total MMSE score decreased as the severity of COPD increases.

Proportions of subjects having exposure to chulha smoke were $16.7 \%$ in mild COPD, $34.5 \%$ in moderate COPD and $21.7 \%$ in severe COPD. Thus proportion of chulha smoke exposure was higher in moderate category followed by severe category. Proportion of smoker was $72.2 \%$ in mild COPD, $65.5 \%$ in moderate COPD and $78.3 \%$ in severe COPD. Thus proportion of male was higher in all three categories and it was nearly similar in all three categories. Mild cognitive impairment rate was 5.6\% in mild COPD, $5.2 \%$ in moderate COPD and $30.4 \%$ in severe COPD. Thus cognitive impairment was very high in severe COPD GOLD stage compare to mild and moderate COPD. Cognitive impairments can be found through all stages of the disease. However, the relation of the severity of symptoms with the stage of severity of COPD is still unclear. Some patients may have no symptoms or complaints until later stages, and some may have many symptoms early on. Especially in the early stages of COPD cognitive impairment is often limited to attention problems and information processing speed. As COPD progresses to a more advanced stage the impairments become more severe and diffuse. Orientation, executive functions and memory seem to be most affected, however, these are also most often researched. The results indicate that there are many possible factors that contribute to cognitive impairment in patients with COPD. One possible contributing factor could be a lack of oxygen, often found in the more severe stages of COPD. A comparison between hypoxemic or oxygen dependent COPD patients and nonhypoxemic/ oxygen dependent patients, showed an effect of lack of oxygen on cognitive functioning. Cognitive impairments were both more severe and diffuse in patients with hypoxemia. This suggests that perhaps in the later stages of COPD hypoxemia and/or hypercapnia, as a result of lack of oxygen, start playing ${ }^{46}$ a more important role in the underlying mechanism of impaired cognitive functioning in COPD. Perhaps the role of lack of oxygen in patients with COPD is an indirect one, by causing other complications such as sleep disturbances (Özge et al., 2006). ${ }^{43}$ Among the subjects having mild cognitive impairment, $81.8 \%$ were smoker while in subjects without any cognitive impairment $68.2 \%$ were smoker. Thus proportion of smoker were higher in mild cognitive impairment group, however this difference was not statistically significant $(\mathrm{P}>0.05)$.

\section{Conclusion}

The present study concludes that patient with chronic obstructive pulmonary disease have significant cognitive impairment compared to healthy controls. The present study concludes that hypoxaemia, hypercapnia, lung function, smoking and BMI are important risk factors for cognitive impairment in COPD patients. Cognitive impairment was very high in severe COPD GOLD stage compare to mild and moderate COPD.

\section{References}

[1] Bellia V, Catalano F, Scichiolone N et al. Sleep disorders in the elderly with and without chronic air flow obstruction: the SARA study. Sleep 2003;26(3):318- 23

[2] Rennard SI. COPD: overview of definitions, epidemiology, and factors influencing its development (review).Chest 1998;113(4):S235-S41.

[3] WHO: Chronic respiratory disease: Definition of COPD. Available at http://www.who.int/respiratory/copd/definition/en/inde x.html

[4] Ortapamuk H, Naldoken S. Brain perfusion abnormalities in chronic obstructive pulmonary disease:comparison with cognitive impairment. Ann Nucl Med $2006 ; 20(2): 99-106$.

[5] Hynninen KM, Breitve $\mathrm{MH}$, Wiborg $\mathrm{AB}$ et al. Psychological characteristics of patients with chronic obstructive pulmonary disease: a review. J Psychosom Res 2005 ;59(6):429-43.

[6] Antonelli-Inc, Corsonello A, Trojano L et al. Correlation between cognitive impairment and dependence in hypoxemic COPD. J Clin Exp Neuropsychol 2008;30(2):141-50.

\section{Volume 4 Issue 12, December 2015}




\section{International Journal of Science and Research (IJSR) ISSN (Online): 2319-7064 \\ Index Copernicus Value (2013): 6.14 | Impact Factor (2014): 5.611}

[7] Allen SC, Jain M, Ragab S et al. Acquisition and shortterm retention of inhaler techniques require intact executive function in elderly subjects. Age Ageing 2003;32(3):299-302.

[8] Antonelli-Inc, Corsonello A, Pedone C et al. Drawing impairment predicts mortality in severe COPD. Chest 2006;130(6):1687-94.

[9] Grant I, Prigatano GP, Heaton RK et al. Progressive neuropsychologic impairment and hypoxemia. Relationship in chronic obstructive pulmonary disease. Arch Gen Psychiatry 1987;44(11):999-1006.

[10] Antonelli-Inc, Marra C, Giordano A et al. Cognitive impairment in chronic obstructive pulmonary disease neuropsychological and spect study. J Neurol 2003;250(3):325-32.

[11] Heaton RK, Grant I, McSweeny AJ et al. Psychologic effects of continuous and nocturnal oxygen therapy in hypoxemic chronic obstructive pulmonary disease. Arch Intern Med 1983;143:1941-7.

[12] Fillit H, Nash DT, Rundek T et al. Cardiovascular risk factors and dementia. Am J Geriatr Pharmacother 2008;6:100-18.

[13] autenschlager NT, Cox KL, Flicker L et al. Effect of physical activity on cognitive function in older adults at risk for Alzheimer disease: a randomized trial. JAMA 2008;300:1027-37.

[14] PS Shankar, Suhail Raoof, Dheeraj Gupta.Textbook of Pulmonary and Critical Care Medicine Vols 1. London. JP Medical Ltd, 2011: 982.

[15] Wig KL, Guleria JS, Bhasin RC et al. Certain clinical and epidemiological patterns of chronic obstructive lung disease as seen in Northern India. Indian J Chest Dis 1964;6:183-94.

[16] Viswanathan R. Epidemiology of chronic bronchitis: morbidity survey in Patna urban area. Indian $\mathrm{J}$ Med Res 1966;54:105-11.

[17] Jindal SK. A field study on follow up at 10 years of prevalence of chronic obstructive pulmonary disease \& peak expiratory flow rate. Indian $\mathrm{J}$ Med Res 1993;98:20-6.

[18] Radha TG, Gupta CK, Singh A et al. Chronic bronchitis in an urban locality of New Delhi - an epidemiological survey. Indian $\mathrm{J}$ Med Res 1977;66:273-85.

[19] Thiruvengadam KV, Raghava TP, Bhardwaj KV. Survey of prevalence of chronic bronchitis in Madras city. In: Viswanathan R, Jaggi OP, editors. Advances in chronic obstructive lung disease. Delhi: Asthma and Bronchitis Foundation of India;1977:59-6.

[20] Ray D, Abel R, Selvaraj KG. A 5-yr prospective epidemiological study of chronic obstructive pulmonary disease in rural South India. Indian J Med Res 1995;101:238-44.

[21] Halbert RJ, Natoli JL, Gano A et al. Global burden of COPD: systematic review and meta-analysis. Eur Respir J 2006;28:523-32.

[22] Dan L. Longo et al. Harrison's Principles of Internal Medicine, 18 Edition. New York. The McGraw Hill Companies,Inc.2011.2156-60.

[23] Takizawa $\mathrm{H}$, Tanaka M, Takami K et al. Increased expression of transforming growth factor-betal in small airway epithelium from tobacco smokers and patients with chronic obstructive pulmonary disease
(COPD). Am J Respir Crit Care Med 2001;163:147683.

[24] Heaton RK, Grant I, McSweeny AJ et al. Psychologic effects of continuous and nocturnal oxygen therapy in hypoxemic chronic obstructive pulmonary disease. Arch Intern Med 1983;143:1941-7.

[25] Chung KF. The role of airway smooth muscle in the pathogenesis of airway wall remodeling in chronic obstructive pulmonary disease. Proc Am Thorac Soc 2005;2:347-54

[26] Vestbo J, Hurd SS, Agusti AG, et al. Global strategy for the diagnosis, management, and prevention of chronic obstructive pulmonary disease: GOLD executive summary. Am J Respir Crit Care Med. 2013;187(4):347-65.

[27] Levy R. Aging-associated cognitive decline. Working Party of the International Psychogeriatric Association in collaboration with the World Health Organization. Int Psychogeriatr. 1994;6(1):63-8.

[28] Anstey KJ, Windsor TD, Jorm AF et al. Association of pulmonary function with cognitive performance in early, middle and late adulthood. Gerontology. 2004;50(4):230-4.

[29] Petersen RC, Stevens JC, Ganguli M et al. Practice parameter: early detection of dementia: mild cognitive impairment (an evidence- based review). Report of the Quality Standards Subcommittee of the

[30] American Academy of Neurology. Neurology. 2001;56(9):1133-42.

[31] Barker DJ, Godfrey KM, Fall C et al. Relation of birth weight and childhood respiratory infection to adult lung function and death from chronic obstructive airways disease. BMJ 1991;303:671-5.

[32] Hung W, Wisnivesky JP, Siu AL et al. Cognitive decline among patients with chronic obstructive pulmonary disease. Am J Respir Crit Care Med 2009;180:134-7.

[33] hakur N, Paul D, Laura J et al. COPD and cognitive impairment: the role of hypoxemia and oxygen therapy. International Journal of Chronic Obstructive Pulmonary Disease 2010;5:263-9.

[34] Negro R, Bonadiman L, Tognella S et al. Extent and prevalence of cognitive dysfunction in chronic obstructive pulmonary disease, chronic non-obstructive bronchitis, and in asymptomatic smokers, compared to normal reference values. International Journal of COPD 2014;9:675-83.

[35] Jing Li and Guang-He Fei. The unique alterations of hippocampus and cognitive impairment in chronic obstructive pulmonary disease. Respiratory Research 2013;14:140.

[36] Gupta PP, Sood S, Atreja A et al. A comparison of cognitive functions in non-hypoxemic chronic obstructive pulmonary disease (COPD) patients and age-matched healthy volunteers using minimental state examination questionnaire and eventrelated potential, P300 analysis. Lung India. 2013;30(1):5-11.

[37] Manju Bhaskar. Psychiatric morbidity and cognitive functioning in chronic obstructive pulmonary diseaseA clinical study. A dissertation submitted to Rajiv Gandhi University of Health science, Bangalore, Karnataka in 2011

\section{Volume 4 Issue 12, December 2015}


[38] Sara C Hitchman, Geoffrey $T$ Fong. Gender empowerment and female-to-male smoking prevalence ratios. Bulletin of the World Health Organization 2009;89:195-202.

[39] Keicho N, Elliott WM, Hogg JC et al. Adenovirus E1A gene dysregulates ICAM-1 expression in transformed pulmonary epithelial cells. Am J Respir Cell Mol Biol 1997;16:23-30.

[40] Elliott WM, Hayashi S, Hogg JC. Immunodetection of adenoviral E1A proteins in human lung tissue. Am J Respir Cell Mol Biol 1995;12:642-8.

[41] Dodd JW, Charlton RA, Martin D et al. Cognitive Dysfunction in Patients Hospitalized With Acute Exacerbation of COPD. CHEST 2013;144(1):119-27.

[42] Gilmour PS, Rahman I, Hayashi S et al. Adenoviral E1A primes alveolar epithelial cells to PM10-induced transcription of interleukin-8. Am J Physiol Lung Cell Mol Physiol 2001;281:L598L606.

[43] Klein M, Gauggel S, Sachs G et al. Impact of chronic obstructive pulmonary disease (COPD) on attention functions. Respiratory Medicine.2010;104(1):52-60.

[44] Ozge C, Ozge A, \& Unal O. Cognitive and functional deterioration in patients with severe COPD. Behavioral Neurology 2006;17:121-30.

[45] Antonelli-Incalzi R, Antonelli G, Marra C et al. Chronic Obstructive Pulmonary Disease: An Original Model of Cognitive Decline. merican Review of Respiratory Disease 1993;148:418-24.

[46] Ranieri P, Bianchetti A, Margiotta A et al. Predictors of 6-month mortality in elderly patients with mild chronic obstructive pulmonary disease discharged from a medical ward after acute nonacidotic exacerbation. $\mathrm{J}$ Am Geriatr Soc 2008;56:909-13.

[47] Shohaimi S, Bingham S, Welch A et al. Occupational social class, educational level and area deprivation independently predict plasma ascorbic acid concentration: a cross-sectional population based study in the Norfolk cohort of the European Prospective Investigation into Cancer (EPIC-Norfolk). Eur J Clin Nutr 2004;58:1432-5. 